Research Article

\title{
Engineering Quantum Dot (Cadmium Sulfide) on Antibodies for Fluoroimmunoassays
}

\author{
Madeeha Shahzad Lodhi (iD) and Zahoor Qadir Samra \\ Applied Molecular Biotechnology Research Lab (AMBR), Institute of Biochemistry and Biotechnology, University of the Punjab, \\ Lahore 54590, Pakistan \\ Correspondence should be addressed to Madeeha Shahzad Lodhi; madeehalodhi.phd.ibb@pu.edu.pk
}

Received 20 December 2019; Revised 22 March 2020; Accepted 26 March 2020; Published 21 April 2020

Academic Editor: Renyun Zhang

Copyright (C) 2020 Madeeha Shahzad Lodhi and Zahoor Qadir Samra. This is an open access article distributed under the Creative Commons Attribution License, which permits unrestricted use, distribution, and reproduction in any medium, provided the original work is properly cited.

\begin{abstract}
Antibodies are good escorts for a therapeutic and diagnostic tool against many diseases as well as for targeting drug delivery and in immunohistochemistry. Cysteine-capped cadmium sulfide (quantum dot) nanoparticles have wide applications in immunohistochemistry due to their unique physical, chemical, and fluorescent properties. In this study, polyclonal antibodies against transferrin (as ligand), doxorubicin (anticancer drug), and $H$. pylori (cancer-causing agent) were developed in rabbits and purified. Purified antibodies were labeled with cadmium sulfide (CdS) quantum dot (QD) and used as a fluorescentlabeled marker for one-step identification in diagnosis and therapeutics. Cysteine-capped CdS QDs were synthesized in the presence of taurine (antioxidant) and characterized by FTIR, VSM, DLS, and TEM. CdS nanoparticles are monodisperse with a narrow size range below $7 \mathrm{~nm}$ and showed an increase of almost $30 \mathrm{~nm}$ after conjugation to IgG. The binding of QD-labeled antibodies was observed and confirmed by binding on MDA-MB 231 cancer cells, mouse liver tissue, mouse tumor tissue, and H. pylori under a fluorescent microscope. QD-labeled antibodies gave sharp fluorescence after binding with their respective targets. Intensity of fluorescence with quantum dot enhances many folds as compared to that of traditional fluorescent-labeled compounds. Experiments are underway to target transferrin and doxorubicin and to analyze the role of $H$. pylori in a mouse model of gastric cancer.
\end{abstract}

\section{Introduction}

Antibodies are the plasma proteins developed in response to antigen for neutralizing the antigen activity [1]. Antibodies are highly important as a therapeutic and diagnostic tool against cancer, autoimmune diseases, and microbial infections, in targeting drug delivery, and in immunohistochemistry. Pharmaceutical industries and research centers have got attraction for antibodies due to vast applications in all biosciences [2].

The development of polyclonal antibodies is cheaper and time-saving as compared to that of monoclonal antibodies [1]. Many animals are used for antibody production including small animals such as mice, rat, rabbits, and guinea pigs to large mammals like goats, sheep, and horses [3, 4]. Among them, rabbit is the commonly used animal for the polyclonal antibody production due to its manageable size and easy handling and bleeding with adequate amount of serum [5].

Antibodies are tagged with different enzymes and fluorescent organic and inorganic compounds for diagnosis in immunochemistry. In fluorescent immunohistochemistry, quantum dot (QD) nanoparticles have unique physical and chemical properties that have an edge over the fluorescent organic compound for immunochemistry [6]. In contrast to traditional fluorescent compounds, cadmium sulfide quantum dot (CdS QD) has the best properties due to photostability and a wide range of excitation wavelength [7].

The goal of the present study was to produce specific antibodies and their conjugation with CdS QD for the characterization of drug and protein in nanocomposite formulation used for targeting drug delivery against cancer as well as to diagnose infections in animal models of gastric cancer. 
In this research model, transferrin was used as ligand and doxorubicin was used as an anticancer drug. H. pylori as a microorganism was used for the induction of inflammation/cancer in a mouse model. Cysteine-capped CdS QD is used as a fluorescent-labeled marker of antibodies.

Transferrin is a carrier glycoprotein that has high affinity with iron and is involved in the depletion of free iron in the blood [8]. The demand of iron by growing cancer cells increased manyfold as compared to normal cells that in turn increase the expression of transferrin receptor in a thousandfold on cancer/tumor cells [9]. Transferrin has proved itself best candidate for therapeutic and diagnostic application. Transferrin also plays an important role in preventing infection because of its iron scavenger action [10]. It is evident that some pathogens develop the ability to express the surface protein that binds the transferrin protein and absorb iron from it [11]. Doxorubicin is used as anticancer medicine and has an anticancer effect in a wide spectrum of cancer. Doxorubicin interacts with DNA and releases free radicals to fragmentize the DNA [12].

Gastric carcinoma is directly related with high salt intake in the diet and persistent of microbial infections of $H$. pylori [13]. Cancer originates from the lining of the stomach by microbial infection or by carcinogenic chemical or due to some genetic alterations [14].

This study was focused for the antibody production and labeling with CdS quantum dot for immunohistochemical studies for targeting transferrin and doxorubicin in $H$. pylori-induced gastric cancer.

\section{Materials and Methods}

\subsection{Polyclonal Antibody Production}

2.1.1. Immunogen Preparation (Transferrin). Purified transferrin was obtained from Applied Molecular Biotechnology Research Lab (AMBR), University of the Punjab, Lahore [15]. Purified transferrin $(80 \mu \mathrm{g}$ in $100 \mu \mathrm{l}$ saline) was emulsified in $100 \mu \mathrm{l}$ of Freund complete adjuvant (FCA) (1:1 ratio) for prime injection in rabbit and then used the same dose in incomplete Freund adjuvant (IFA) for booster injections [16].

\subsubsection{Drug (Doxorubicin) Immunogen Preparation. Doxoru-} bicin was conjugated with BSA and OVA separately (BSA, for immunization, and OVA, for characterization) by a two-step glutaraldehyde method as described [17].

\subsubsection{H. pylori Immunogen Preparation. H. pylori strain was} provided by AMBR and cultured for 8-9 days under microaerophilic conditions $\left(10 \% \mathrm{CO}_{2}\right.$ and $\left.5 \% \mathrm{O}_{2}\right)$ in brain heart infusion medium supplemented with $10 \%$ fetal bovine serum at $37^{\circ} \mathrm{C}$. Bacterial cells were harvested by centrifuging at $10,000 \mathrm{~g}$ for 10 minutes at $4^{\circ} \mathrm{C}$ and carefully washed with PBS. The washed cells of $H$. pylori was treated with $0.5 \%$ formalin in PBS and kept at $4^{\circ} \mathrm{C}$ for 2 hours. After fixation, treated $H$. pylori was again washed three times with 1x PBS to remove the traces of formalin. Fixed cells were used as immunogen.
2.1.4. Immunization and Purification of Antibodies. Rabbits were used for the production of antibodies against transferrin, doxorubicin, and H. pylori. Six New Zealand white rabbits (two for each sample) were housed under standard conditions. Before immunization, preimmune blood was drawn from each rabbit. Serum was isolated and stored at $-20^{\circ} \mathrm{C}$ for using it as control. A total of $80-100 \mu \mathrm{g}$ of transferrin, 250-300 $\mu \mathrm{g}$ of BSA-conjugated doxorubicin, and $1 \times 10^{7}$ H. pylori cells were suspended in $100 \mu \mathrm{l}$ of normal saline and mixed with $100 \mu \mathrm{l}$ of FCA in a 1:1 ratio. Rabbits were injected through subcutaneous route at four different sites (50 $\mu \mathrm{l}$ at each site). Primary injection was followed by four booster injections after 15-day intervals with the same dose $(100 \mu \mathrm{l})$ of immunogens in $100 \mu \mathrm{l}$ of IFA $(1: 1$ ratio) at four different subcutaneous sites. Each rabbit was bled from marginal ear vein after a booster dose and tested for the presence of specific antibodies such as anti-transferrin, anti-doxorubicin, and anti-H. pylori.

Immunized blood was collected by cardiac puncture, and rabbits were anesthetized with $35 \mathrm{mg} / \mathrm{kg}$ of ketamine chloride and $5 \mathrm{mg} / \mathrm{kg}$ xylazine by intramuscular injection [18]. Serum was separated, aliquoted, and stored at $-20^{\circ} \mathrm{C}$. Antibodies were further purified from the stored serum samples by using $\mathrm{NAB}^{\mathrm{TM}}$ spin columns (affinity A/G column) under the given instructions. Purified anti-transferrin, anti-doxorubicin, and anti-H. pylori were characterized by ELISA, immunoslot blot and Western blot analysis under nature and denature conditions. Antibody titer and dilution factors were also calculated by ELISA.

\subsection{Antibody Characterization}

2.2.1. Enzyme-Linked Immunosorbent Assay. $10 \mu \mathrm{l}$ of purified antigens $(1.0 \mathrm{mg} / \mathrm{ml}$ of purified transferrin, dox-OVA conjugates, and $1 \times 10^{6} \mathrm{H}$. pylori) was diluted in $200 \mu \mathrm{l}$ of $0.05 \mathrm{M}$ carbonate buffer, $\mathrm{pH}$ 9.0, and coated on to a microtiter ELISA plate (in triplicate). The plates were incubated for two hours with gentle shaking at $100 \mathrm{rpm}$. After antigen coating, the nonspecific sites were blocked for one hour at $37^{\circ} \mathrm{C}$ with $5 \%$ skim milk in $1 \mathrm{x}$ TBS $(50 \mathrm{mM} \mathrm{NaCl}$ and $150 \mathrm{mM}$ Tris, $\mathrm{pH}$ 7.5). After washing with TBS, an antigen-specific purified primary antibody $(1: 100$ dilutions in $50 \mathrm{mM}$ Tris-Cl buffer, $\mathrm{pH}$ 8.5) was added to each antigen-specific well and incubated for one hour at $37^{\circ} \mathrm{C}$. Again after washing the wells, HRP-conjugated secondary antibody (HRP-conjugated goat anti-rabbit IgG 1:5000 dilutions in $50 \mathrm{mM}$ Tris- $\mathrm{Cl}$ buffer, $\mathrm{pH}$ 8.5) was added in each well and incubated further for one hour at $37^{\circ} \mathrm{C}$. After washing, HRPO-specific substrate $1 \%$ tetramethyl benzidine and $0.1 \% \mathrm{H}_{2} \mathrm{O}_{2}$ were added in each well and the results were observed [19].

Antibody titer and dilution factor were determined by ELISA as the substrate reaction was stopped by sulfuric acid and was noted at $405 \mathrm{~nm}$ in an ELISA plate reader.

2.2.2. Immunoslot Blot Analysis. The reactivity of antibodies with antigen was also checked on a nitrocellulose membrane (NC) under denature conditions. $50 \mu \mathrm{l}(10 \mu \mathrm{g} / \mu \mathrm{l})$ of each antigen (transferrin, OVA-doxorubicin conjugates, H. pylori as described in ELISA) was prepared as described above and 
denatured at $70^{\circ} \mathrm{C}$ for 30 minutes. The denatured antigens were loaded on the NC membrane by a hybrid slot blot apparatus (Bethesda Research Laboratories, USA). After blocking nonspecific sites on the nitrocellulose membrane with $5 \%$ skim milk in TBS for 2 hours with gentle shaking, the antigen-specific purified primary antibodies (1:500 dilutions) were allowed to react with antigen onto the nitrocellulose membrane for one hour under gentle shaking. After washing the nitrocellulose membrane with TBS, secondary antibodies (goat anti-rabbit-HRPO-conjugated 1:5000 dilution) were added and allowed to react with primary antibodies. Again, after washing, the blots were exposed to a HRPOspecific substrate ( $1 \%$ diaminobenzidine and $0.1 \% \mathrm{H}_{2} \mathrm{O}_{2}$ ) and the results were noted [19].

2.2.3. Western Blot Analysis. Western blot was also conducted to verify the reactivity of antibodies with transferrin. Briefly, transferrin was run on 10\% SDS-PAGE and transferred onto the nitrocellulose membrane by a semidry method (Bio-Rad). The presence of protein onto the nitrocellulose membrane was confirmed by Ponceau S stain. After washing, the nitrocellulose membrane was treated with $5 \%$ skim milk and then primary and secondary antibodies as described in the immunoslot blot analysis. Results were noted [20].

\subsection{Synthesis of Cysteine-Capped Cadmium Sulfide Quantum} Dot (Cys-CdS QD). Cysteine-capped cadmium sulfide QDs were synthesized in the presence of taurine as an antioxidant. A $0.01 \mathrm{M}$ cadmium acetate solution ( $\mathrm{pH}: 8)$ and $0.01 \mathrm{M} \mathrm{L-}$ cysteine solution ( $\mathrm{pH}: 8)$ were refluxed in $200 \mathrm{ml}$ reaction volume for 30 minutes in the presence of a final concentration of $0.1 \mathrm{M}$ taurine. Then, $0.01 \mathrm{M}$ sodium sulfide in $10 \mathrm{ml}$ deionized water was added dropwise in a reaction mixture and refluxed further for 12 hours. Addition of taurine as an antioxidant prevents the surface oxidation of QD synthesized in the presence of air and improves the size and fluorescent quality of QDs. After the addition of $\mathrm{Na}_{2} \mathrm{~S}$, a yellow color of suspended particles was observed that indicated the onset of reaction.

\subsection{Conjugation of Cysteine-Capped CdS QD Nanoparticles} with Rabbit Polyclonal IgG. Purified and characterized rabbit polyclonal IgG was cross-linked with cysteine by a 1-Ethyl-3[3-dimethylamino propyl]carbodiimide (EDC) method. $0.01 \mathrm{~g}$ of cysteine-capped CdS QD was taken in one $\mathrm{ml}$ of deionized water and a $\mathrm{pH}$ of 8 was adjusted with $\mathrm{NaOH}$. One $\mathrm{ml}$ of EDC $(20 \mathrm{mg} / \mathrm{ml}$ of deionized water $)$ was added for carboxylic group activation, and a $\mathrm{pH}$ of 6.4 was adjusted with $1 \mathrm{M} \mathrm{HCl}$. The reaction mixture was incubated for 30 minutes in the dark with continuous shaking at $100 \mathrm{rpm}$. After 30-minute incubation, one $\mathrm{ml}$ of carbodiimide $(10 \mathrm{mg} / \mathrm{ml}$ of deionized water) along with $100 \mu \mathrm{l}$ of purified rabbit IgG (anti-transferrin, anti-doxorubicin and anti- $H$. pylori) $(1 \mu \mathrm{g} / \mu \mathrm{l})$ was added separately and incubated further for 2 hours at $37^{\circ} \mathrm{C}$ in the dark with continuous shaking at $100 \mathrm{rpm}$. The conjugated particles were separated by centrifuging at $14000 \mathrm{~g}$ for 10 minutes at $4^{\circ} \mathrm{C}$ and washed twice with PBS. The washed nanocomposites were suspended in $1 \mathrm{x}$ TBS buffer for further use or stored at $-20^{\circ} \mathrm{C}$.

2.5. Characterization of Nanocomposites. Synthesized cysteine-capped $\mathrm{CdS}$ and its conjugates with antibodies were characterized by UV-Vis spectroscopy (PG instrument, Model T90+), excitation and emission spectra (PerkinElmer fluorescent spectrophotometer, LS45), fluorescent microscopy under different filters (Olympus BX51), FourierTransform Infrared spectroscopy (FTIR, Agilent Technology Cary 630), Transmission Electron Microscopy (TEM, JEOL JEM-1010), and dynamic laser scattering analyzer (HORIBA Scientific, nanopartica SZ-100) techniques under standard conditions.

\subsection{Receptor Binding Studies}

2.6.1. Quantum Dot-Linked Immunosorbent Assay. $10 \mu \mathrm{l}$ of purified antigens $(1.0 \mathrm{mg} / \mathrm{ml}$ of purified transferrin, DoxOVA conjugates, and $1 \times 10^{6} \mathrm{H}$. pylori cells) was diluted separately in $200 \mu \mathrm{l}$ of $0.05 \mathrm{M}$ carbonate buffer, $\mathrm{pH} 9.0$, and coated onto a microtiter ELISA plate and incubated for two hours with gentle shaking at $100 \mathrm{rpm}$ (in triplicate). The nonspecific sites were blocked for one hour at $37^{\circ} \mathrm{C}$ with $5 \%$ skim milk in $1 x$ TBS. After washing with TBS, an antigen-specific quantum dot-linked primary antibody (1:100 dilutions in $50 \mathrm{mM}$ Tris-Cl buffer, $\mathrm{pH} 8.5$ ) was added to each antigenspecific well for one hour at $37^{\circ} \mathrm{C}$. Fluorescence was observed on a UV plate in the presence of antibodies and then washed three times with TBS buffer. After washing, wells were filled with deionized water and again, fluorescence was observed on a UV plate.

\subsubsection{Immunohistochemical Studies}

(1) Binding Efficiency of Rabbit Anti-Transferrin Antibody. An anti-transferrin antibody binding with transferrin, bound with its receptor, was checked on MDA MB 231 cancer cells and mouse liver tissue section. MDA MB 231 cells were grown under microaerophilic conditions in a humidified chamber on gelatin-coated coverslips. The growing adhered cells on the coverslip were fixed with $4 \%$ paraformaldehyde for 15 minutes and covered with $5 \mu \mathrm{g}$ of purified transferrin and incubated for $20-25$ minutes at $37^{\circ} \mathrm{C}$. The cells were washed with PBS for 5 minutes to remove the unbound transferrin and then covered with 5\% skim milk. Again, after washing, cells were incubated with QD-conjugated rabbit anti-transferrin (1:100 dilutions) antibodies for 2530 minutes. After washing, stained cells were observed under a fluorescent microscope.

Paraformaldehyde-lysine-periodate (PLP) fixed liver tissue was obtained from AMBR and cut into small $5 \mathrm{~mm}$ cubes. Tissue dehydration was done by ascending series of sucrose gradient $(10 \%, 15 \%, 20 \%$, and $25 \%)$ and then embedded in an OCT compound. Sections of 6-8 $\mu \mathrm{m}$ size were cut in cryostat machine (Leica, Germany), collected on albumin-coated slides, and proceeded further for staining with QD-labeled antibodies as described above. Sections were observed under 


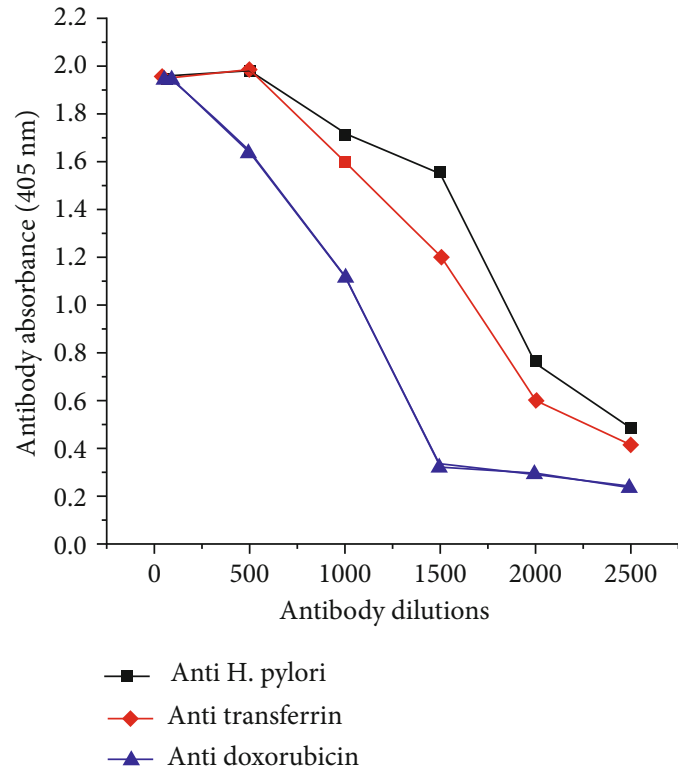

(a)

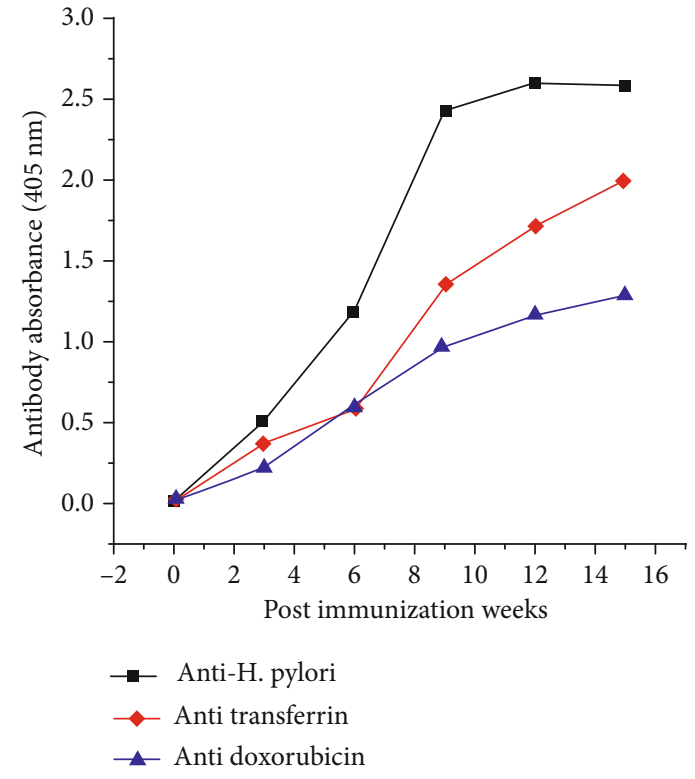

(b)

FIGURE 1: The end titer of purified antibodies after 14 weeks of immunization. (a) Best dilution factor for anti-transferrin and anti $H$. pylori is $1: 500$ and for anti-doxorubicin $1: 100$. (b) The humoral response at different time intervals during immunization. Antibody concentration was low at four weeks and reaches to a higher level after 12 weeks.

a fluorescent microscope using a blue excitation filter (Olympus BX51).

(2) Binding Efficiency of Rabbit Anti-Doxorubicin Antibody. Binding efficiency of QD-conjugated anti-doxorubicin antibodies with doxorubicin was checked on MDA MB 231 cancer cells and on a mammary tumor tissue section of mouse. MDA MB 231 cells were incubated with doxorubicin and fixed as described above. Fixed cells were washed with TBS and treated with by $5 \%$ skim milk for 30 minutes. The cells were exposed to anti-doxorubicin antibodies for one hour, and after washing, cells were observed under a fluorescent microscope.

Mouse with mammary gland tumor was obtained from the animal house of AMBR, and doxorubicin ( $50 \mu \mathrm{g} / \mathrm{saline})$ was injected near the tumor. After one hour, the mouse was dissected by following the standard procedure and tumor was collected. Tumor tissue was fixed in paraformaldehyde-lysineperiodate (PLP) fixative, and immunohistology was completed as described above using anti-doxorubicin antibodies. Stained tissue sections were observed under a fluorescent microscope.

(3) Binding Efficiency of Rabbit Anti-H. pylori Antibody. $\mathrm{H}$. pylori culture suspension $(20 \mu \mathrm{l})$ was taken on albumin-coated glass slides, and smear was prepared. $100 \mu \mathrm{l}$ (1:100 dilutions) of QD-conjugated anti- $H$. pylori antibody was added onto the smear. After one hour of incubation, the slide was washed with PBS and observed under a fluorescent microscope.

\section{Results}

3.1. Characterization of Antibodies. Polyclonal antibodies were generated against transferrin protein, doxorubicin drug, and $H$. pylori microorganisms. The titer of the antibodies was also checked during immunization process (Figure 1).

The specificity and reactivity of affinity-purified antibodies towards their specific antigens were checked under nondenaturing and denaturing conditions. Greenish blue color formation in ELISA and appearance of brown precipitates in immunoslot blots (Figure 2(a)) confirmed the specific reactivity of antibodies with their respective antigens. Antitransferrin reactivity and specificity were further confirmed by Western blot under denature conditions. Transferrin band was appeared at $\sim 78 \mathrm{KDa}$ after Coomassie staining (Figure 2(b)) and brown precipitates at $78 \mathrm{KDa}$ on the nitrocellulose membrane (Figure 2(c)) confirmed the reactivity of anti-transferrin with transferrin.

\subsection{Characterization of Cysteine-Capped CdS QD and Labeling with Antibodies}

3.2.1. Optical Characterization. UV-VIS spectra of cysteinecapped and IgG-conjugated CdS QD are shown in Figure 3. The UV-VIS spectra showed a clear blue shift in wavelengths as compared to CdS salt $(512 \mathrm{~nm})$ that was the indication of the QD nanoparticle synthesis. Cysteine-capped CdS QD synthesized in the presence of taurine showed a greater blue shift in wavelength and broad absorption peak (Figure 3(a)). A stable absorption spectrum of IgG-conjugated cysteinecapped CdS QD was observed (Figure 3(b)).

Excitation and emission spectra were collected by fluoroscopic analysis (Figure 4). A single excitation and emission spectrum peak of cysteine-capped CdS QD is shown in (Figure 4(a)) while IgG-conjugated CdS QD showed two emission peaks (Figure 4(b)). Different intensities of fluorescence were observed for cysteine-capped CdS QD and IgG- 




(a)

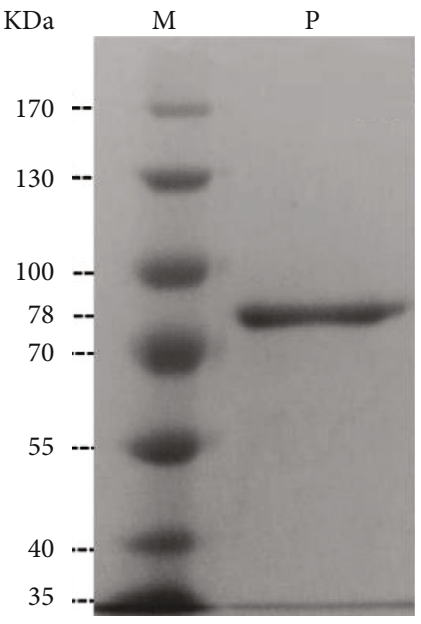

(b)

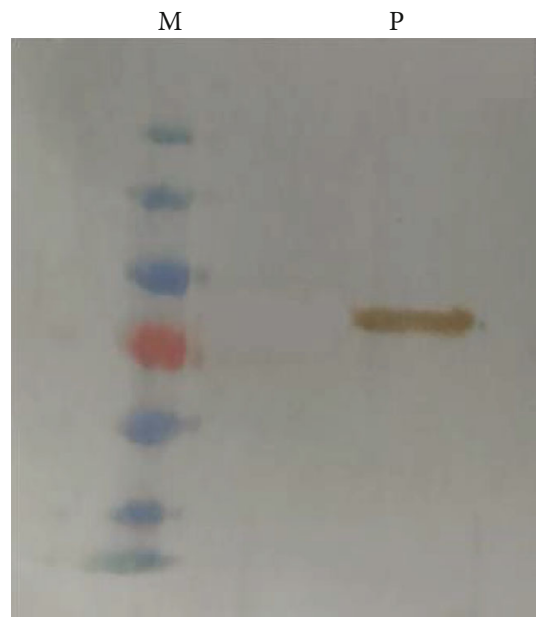

(c)

FIGURE 2: Immunocharacterization of purified rabbit polyclonal IgG. (a) Immunoslot blot shows the successful binding of antibodies to their respective antigen. (b) SDS-PAGE shows a single band of transferrin protein of $78 \mathrm{KDa}$. (c) Western blot confirms the specificity of antitransferrin antibodies.

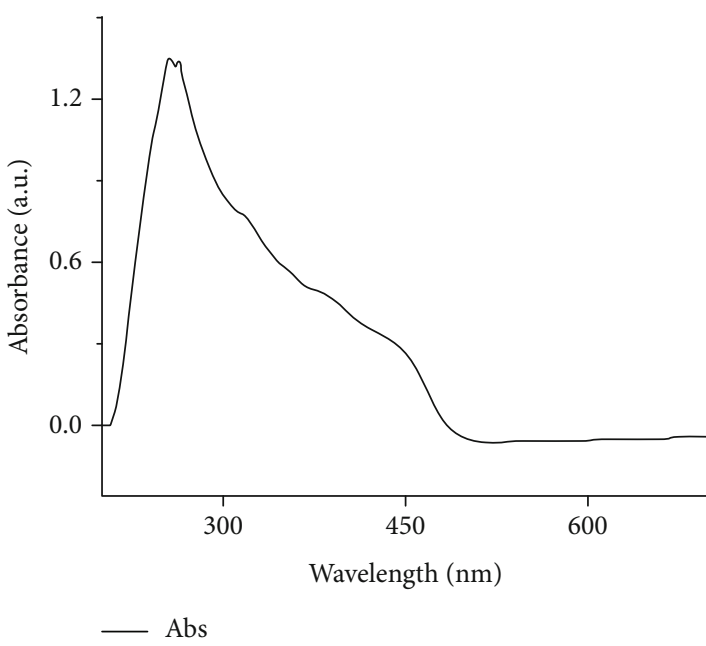

(a)

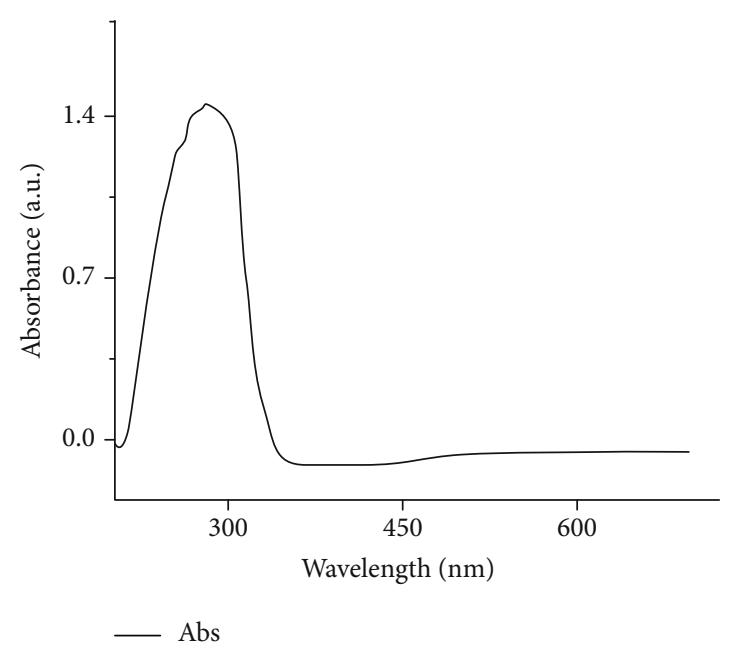

(b)

FIGURE 3: UV-VIS spectroscopy of CdS nanocomposites and its conjugates. Spectrum of (a) cysteine-capped CdS QD and (b) IgG-conjugated cysteine-capped CdS QD.

conjugated cysteine-capped CdS QD. Fluorescent properties of nanoparticles were further observed under UV and blue filters of a fluorescent microscope, and particles appeared blue and green, respectively (Figures 4(c) and 4(d)).

3.2.2. Structural Analysis. FTIR analysis of nanocomposites is shown in Figure 5. The FTIR spectrum of cysteine with characteristic SH peak $\left(2549.7 \mathrm{~cm}^{-1}\right)$ and associated carboxylic $\left(1575.5 \mathrm{~cm}^{-1}\right.$ and $\left.1387.0 \mathrm{~cm}^{-1}\right)$ and amine $\left(3166.1 \mathrm{~cm}^{-1}\right)$ peaks is given in Figure 5(a). The spinal structure of nascent $\mathrm{CdS}$ QD FTIR spectrum is shown in Figure 5(b) and cysteinecapped CdS QD is given in Figure 5(c). Characteristic SH peak of cysteine disappeared due to covalent attachment of cysteine to CdS, and all cysteine-associated peaks were observed on the spinal structure of CdS QD. Primary amine
$\mathrm{NH}_{2}$-associated peaks were clearly visible between 3280 and $3340 \mathrm{~cm}^{-1}$ and carboxylic COO-associated peaks in region $1540-1600 \mathrm{~cm}^{-1}$ and $1390-1410 \mathrm{~cm}^{-1}$. Figure 5(d) shows visible changes in peak patterns and intensities that confirmed the successful conjugation of IgG with cysteine-capped CdS QD.

The schematic presentation of cadmium sulfide quantum dot engineering with antibodies is shown in Figure 6. The model presents the different orientation possibilities of antibodies on cysteine-capped cadmium sulfide quantum dot.

3.2.3. Morphology and Size Characterization. Dynamic light scattering (DLS) analysis of particles showed the size and dispersity of CdS QD nanoparticles (Figure 7). All nanoparticles showed monodispersity and a narrow size range. DLS analysis of cysteine-capped CdS QD showed nanoparticle 


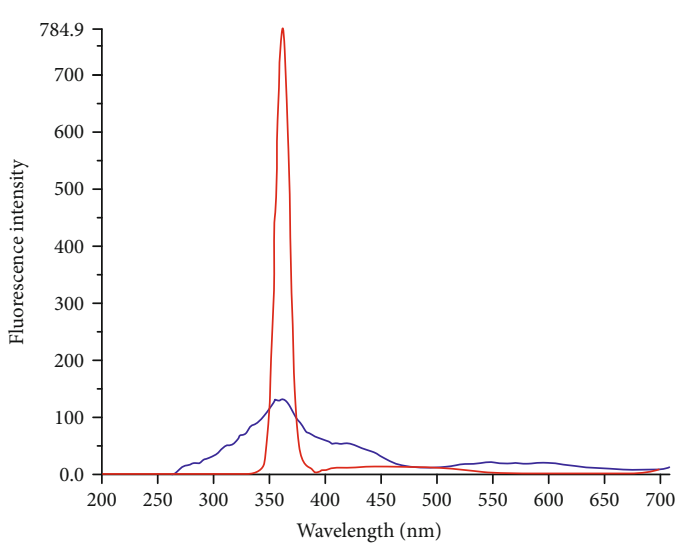

(a)

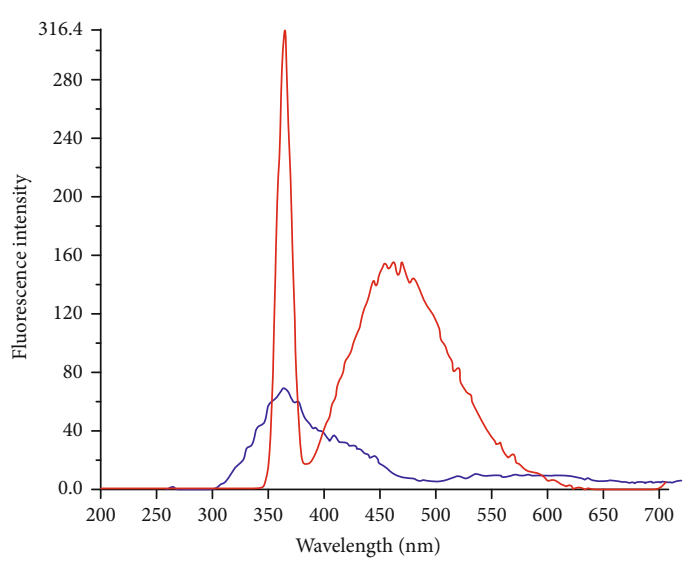

(b)
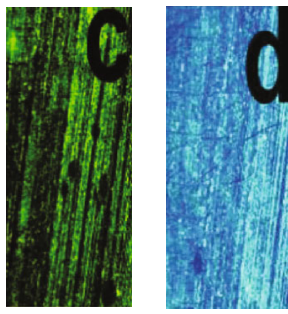

(c)

(d)

FIGURE 4: Fluorescent study and excitation and emission spectra of nanocomposites. (a) Cysteine-capped CdS QD in taurine presence with a maximum excitation of 361.5 and maximum emission of 362.8. (b) Rabbit polyclonal IgG-conjugated cysteine-capped CdS QD with a maximum excitation of 363.6 and maximum emission of 365.2. (c, d) The fluorescence observation of nanoparticles under UV excitation and blue excitation filters.

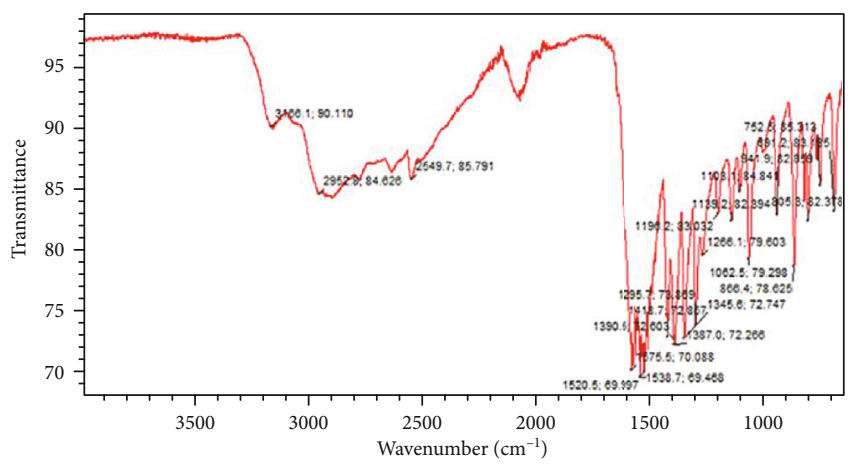

(a)



(c)

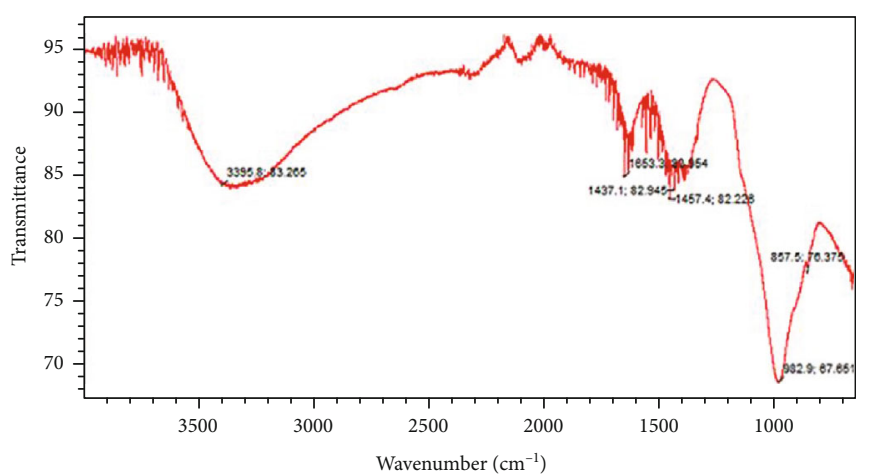

(b)

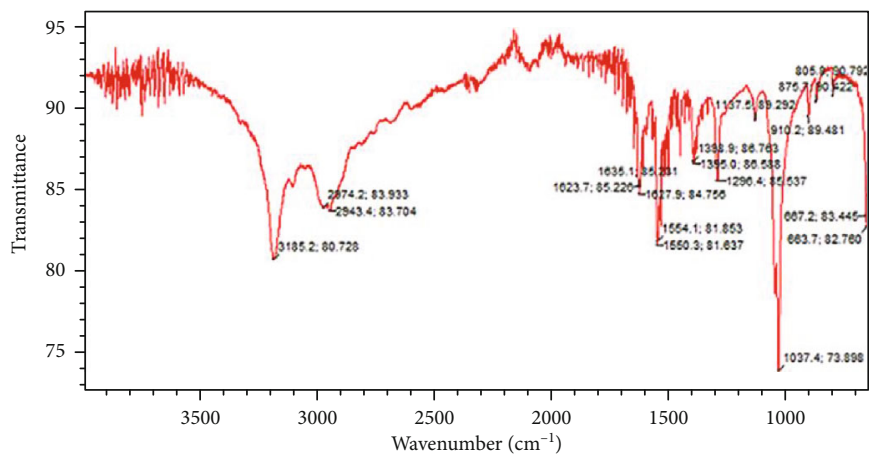

(d)

FIgURE 5: FTIR analysis. (a) This shows the FTIR spectrum of L-cysteine. (b) Spectrum of bare CdS QD shows the specific spinal structure of CdS QD with associated peaks. (c) Spectrum of cysteine-capped CdS QD confirmed the successful capping of CdS with cysteine because of the absence of SH peak and appearance of amine and carboxylic peaks. (d) Spectrum of rabbit polyclonal IgG-conjugated cysteine-capped CdS QD showed successful binding of proteins because of the change in peak patterns and intensities.

distribution in a size range of 0.4 to $3 \mathrm{~nm}$ and fewer in range of 10 to $60 \mathrm{~nm}$ with an overall mean size of $6 \mathrm{~nm}$ and a Polydispersity index (PI) of 0.214 (Figure $7(\mathrm{a})$ ). The DLS analysis of IgG-conjugated nanocomposites with an increase of approximately $30 \mathrm{~nm}$ in size was observed (Figure 7(b)). IgG-conjugated cysteine-capped CdS QDs were fallen in a size range of 10 to $100 \mathrm{~nm}$ with a mean size of $30 \mathrm{~nm}$ and a PI value of 0.334 . TEM micrographs of nanoparticles are 


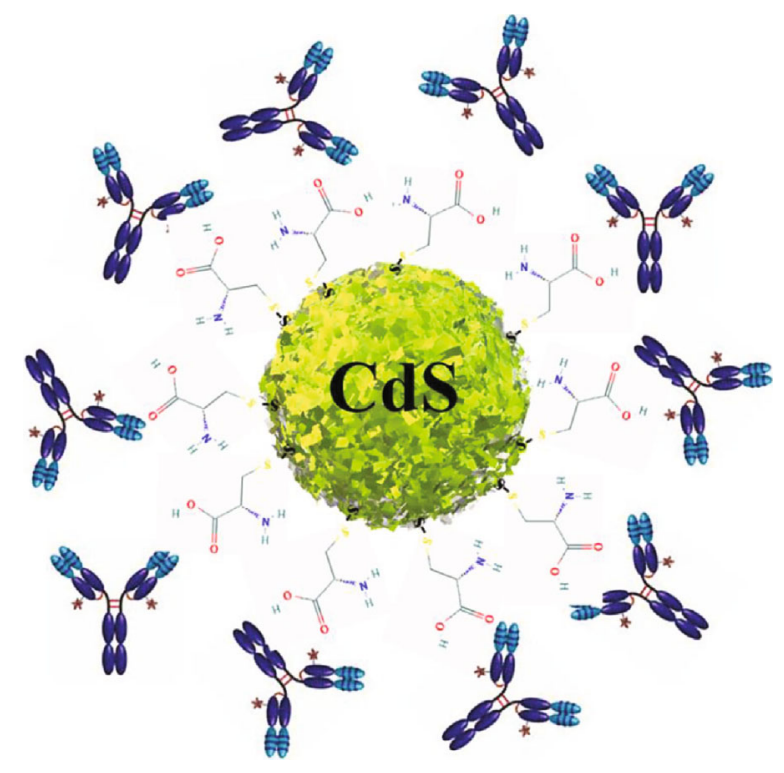

FIGURE 6: Schematic model of IgG conjugation to CdS QD. The model shows the conjugation of amine groups on the antibody with the carboxylic group of cysteine-capped cadmium sulfide quantum dot.

shown in Figures 7(c) and 7(d) which further confirmed the DLS analysis. Micrograph of cysteine-capped CdS QD showed spherical-shaped monodisperse particles of a size below $7 \mathrm{~nm}$ (Figure $7(\mathrm{c})$ ). After conjugation with $\operatorname{IgG}$, an increase of almost $30 \mathrm{~nm}$ was observed but particles retain the spherical shape, as shown in Figure 7(d).

3.3. Quantum Dot-Linked Immunosorbent Assay (QD-LISA). Fluorescent analysis of antigen binding with QD-conjugated rabbit IgG was conducted. Fluorescence in the wells was observed on a UV lamp tray in the presence of QDconjugated antibodies before washing (Figure 8(a)) and in the presence of deionized water after washing (Figure 8(b)). Strong fluorescence was observed in both cases. QDconjugated antibody binding with antigen were also observed under a fluorescent microscope. Nanoparticles were clearly observed (Figures $8(\mathrm{c})$ and $8(\mathrm{~d})$ ) that confirmed the binding of antibodies with their respective antigens on microtiter wells.

3.4. Immunohistochemical Studies. Histochemical studies about the binding of CdS-conjugated rabbit anti-transferrin, anti-doxorubicin, and anti- $H$. pylori with their respective antigens were further studied.

3.4.1. Anti-Transferrin Antibody Binding Studies. Observation of the stained MDA-MB 231 cells (Figure 9(a)) and mouse liver tissue section (Figure 9(b)) with QDconjugated anti-transferrin antibody under blue excitation confirmed the binding at specific sites. The cells and tissue exposed to nonconjugated anti-transferrin antibodies were devoid of any fluorescence.

3.4.2. Anti-H. pylori Antibody Binding Studies. The binding of rabbit anti-H. pylori antibody to Anti- $H$. pylori surface proteins in immunohistochemistry is shown in Figures 9(c) and $9(\mathrm{~d})$.
3.4.3. Anti-Doxorubicin Antibody Binding Studies. Doxorubicin carried MDA-MB 231 cells, and tumor tissues expressed to doxorubicin were incubated with anti-doxorubicin antibodies and observed under a fluorescent microscope. Fluorescence observation of unstained MDA-MB 231 cancer cells and tumor tissue sections under green filters confirmed the uptake of doxorubicin by cells (Figures 10(a) and 10(c)), while stained MDA-MB 231 cells (Figure 10(b)) and tumor tissue section (Figure 10(d)) with QD-conjugated antidoxorubicin antibody were observed under a blue excitation filter, and it confirmed the targeted binding at specific sites.

\section{Discussion}

Antibodies are not only known as therapeutic escorts against cancer, autoimmune diseases, and microbial infections but also act as an essential tool for diagnosis. Three different types of molecular moieties were selected for the development of polyclonal antibodies used in immunohistochemical studies. In this study, transferrin as a protein, doxorubicin as a hapten, and $H$. pylori as a microorganism were selected due to their applications as important clinical tools for targeting, prognosis, and diagnosis, respectively.

Transferrin is an iron-binding glycoprotein, and the transferrin-specific receptor expression increased on cancer cells. Iron is an essential nutritional element required for many biological functions, and correlation is reported between cancer cells and transferrin receptor expression $[21,22]$. That can be justified due to high iron demand of abruptly growing cells for their DNA manipulation and energy cycles involved in cell cycle progression $[23,24]$. This relationship makes transferrin receptor an important target for targeting drug delivery by using either transferrin protein $[25,26]$ or anti-transferrin receptor antibody [27]. Other than transferrin applications for targeting drug delivery, transferrin also has free-iron sequestering, antioxidative, and antimicrobial actions that enhance its importance in several therapeutic applications including reperfusion injury, ischemia, organ transplantation, and cardiovascular diseases [28-31].

Doxorubicin is an anthracycline antibiotic used in chemotherapy and treatment of solid tumor. Many studies were focused on the use of doxorubicin widely as a chemotherapeutic agent loaded on or conjugated to nanomaterials [12, 32] or peptides [33-35] for targeted drug delivery. Therefore, anti-doxorubicin antibodies may be useful in characterization of designed nanomedicines or nanocomposites.

H. pylori is a gram-negative bacterium that colonizes the gastric epithelial cells and infects almost half of the world population. Gastric H. pylori infection causes gastric ulceration [36], and prolonged colonization leads to site-specific diseases including dreadful gastric cancer [37, 38]. Early diagnosis and eradication of $H$. pylori can prevent the onset of gastric cancer [39]. Application of QD conjugated with anti $H$. pylori antibodies for diagnosis of $H$. pylori infection in biopsy samples will help in the diagnosis at the early stages of infection. 


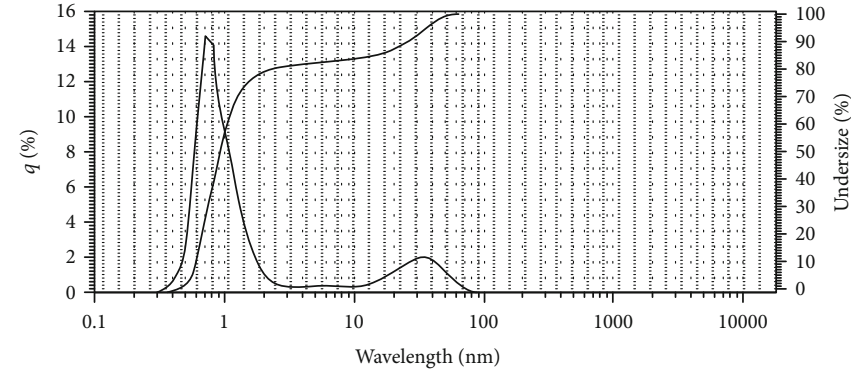

(a)

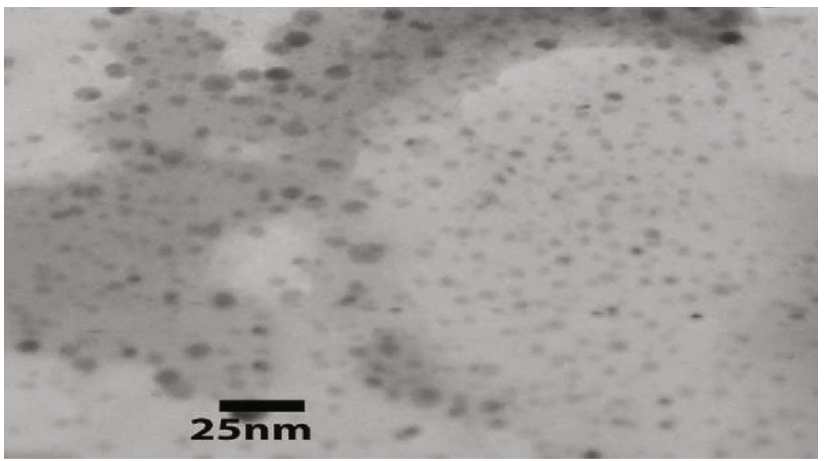

(c)



(b)

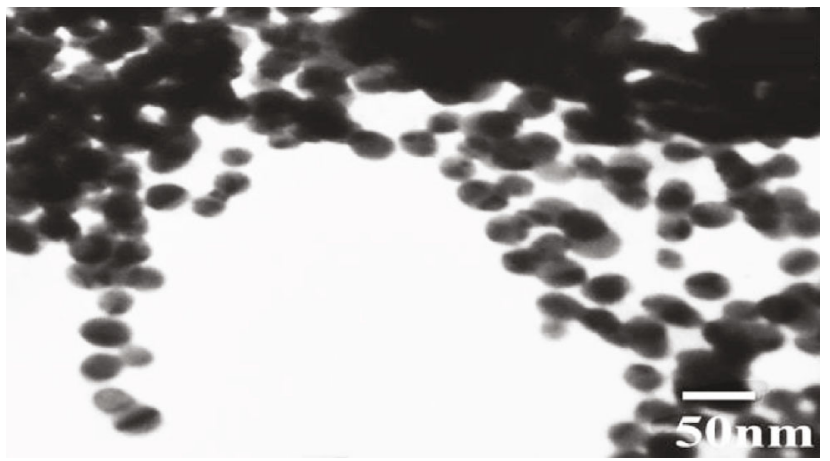

(d)

FIgURE 7: DLS and TEM analysis. (a) The DLS analysis of cysteine-capped CdS QD shows particles in a size range of 0.4 to $3 \mathrm{~nm}$ and fewer in 10 to $60 \mathrm{~nm}$ with a mean size of $6 \mathrm{~nm}$. (b) The DLS analysis of IgG-conjugated cysteine-capped CdS QD shows particles in a size range of 10 to $100 \mathrm{~nm}$ with an increase of $30 \mathrm{~nm}$ in size with a mean size of approximately $30 \mathrm{~nm}$. (c) TEM image of cysteine-capped CdS QD synthesized in taurine presence $(25 \mathrm{~nm}$ scale) shows the monodisperse spherical particles in a size below $7 \mathrm{~nm}$. (d) TEM image (50 nm) shows the uniform distribution of IgG-conjugated cysteine-capped CdS QD with a spherical shape and mean size of $30 \mathrm{~nm}$.

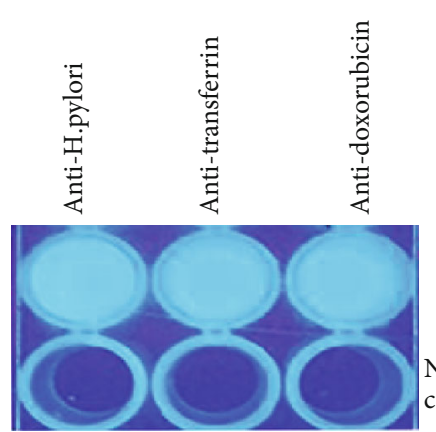

(a)

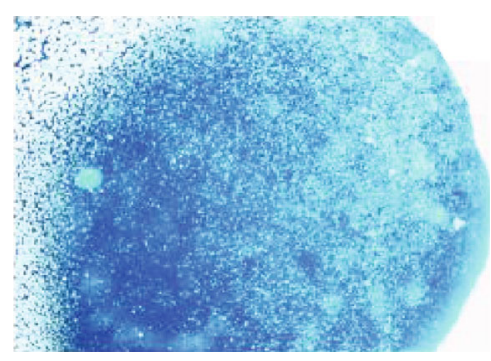

(c)



(b)

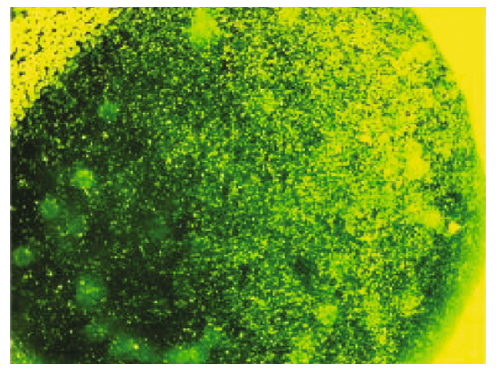

(d)

FIGURE 8: Quantum dot-linked immunosorbent assay. (a) The fluorescent observation of microtiter wells with QD-linked antibodies on a UV lamp tray. (b) The fluorescent observation of microtiter wells after washing with TBS and filling with deionized water on the UV lamp tray. (c) Observation under a UV filter of a fluorescent microscope gives a blue color. (d) Observation under a blue excitation filter gives a green color and confirmed the binding of antibodies with antigen. 


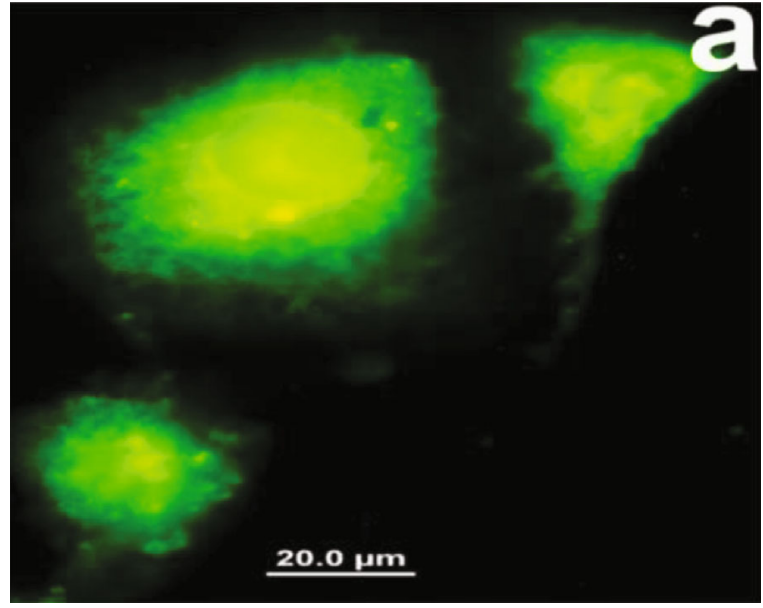

(a)

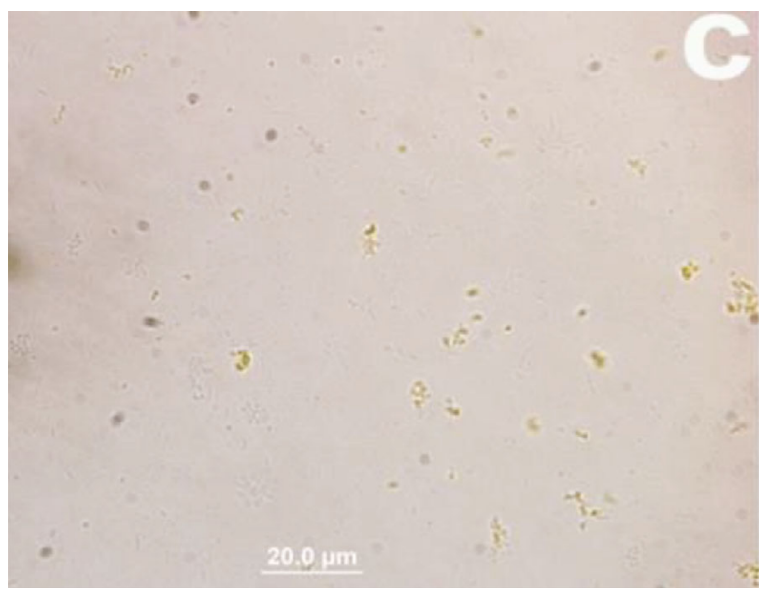

(c)

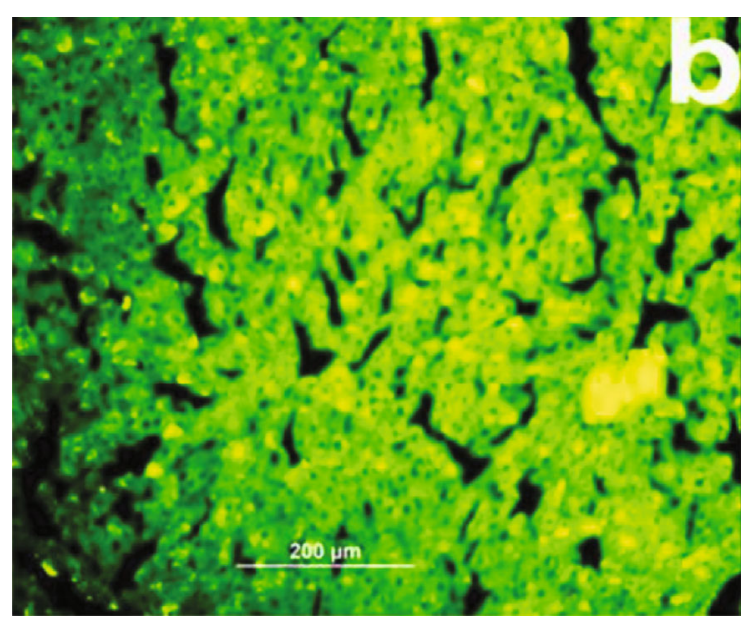

(b)

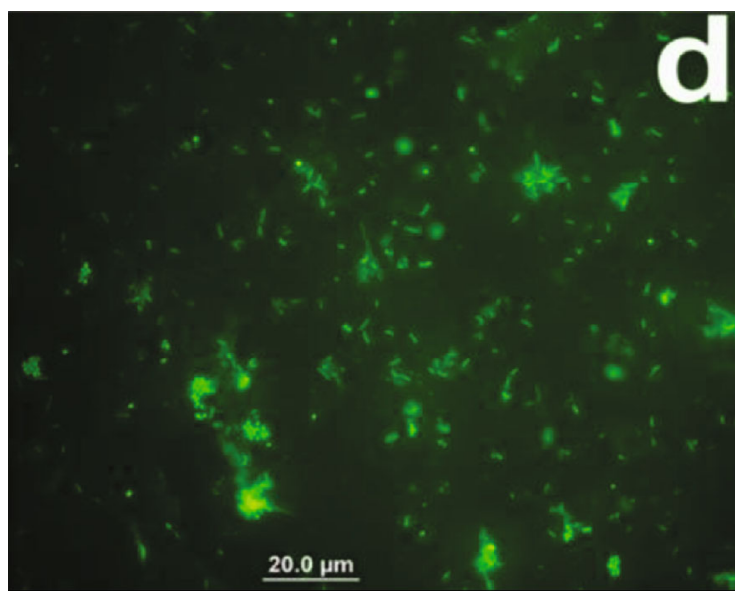

(d)

FIGURE 9: Immunohistochemical study of anti-transferrin and anti H. pylori binding. (a, b) Binding of anti-transferrin antibody to transferrin present on transferrin receptors on MDA-MB 231 cancer cells and mouse liver tissue sections is confirmed. (c, d) Observation under a brightfield and fluorescent microscope confirms the anti- $H$. pylori binding with $H$. pylori surface proteins.

Rabbits were selected for antibody production because of many factors. Rabbits offer many advantages for the development of polyclonal antibodies over other laboratory animals due to body size, easy housing, and easy collection of immunization blood to check antibody titer [5, 40, 41]. After the completion of the immunization process, blood was collected by cardiac puncture and antibodies were purified using A/G affinity columns.

QDs are smaller size, unique semiconductor nanoparticles, and their photoluminescence and chemical properties depend on their sizes. Cysteine-capped CdS QDs were synthesized in the presence of taurine and characterized. Cysteine-capped CdS QD showed smaller and narrow size distribution as compared to bare CdS QD. Bare CdS QD showed higher coalescence, and due to this property, it is necessary to cap them with some organic cover to protect the reactivity of particles with air oxygen and moisture [42-44]. QD nanoparticles are synthesized in inert atmosphere to avoid the damage of precursors and formation of metal oxide as a side product and also to protect the luminescence properties of QD [42]. Here in this research work, a novel method is reported for the synthesis of CdS QD in the presence of taurine (antioxidant) to get a smaller size good-quality CdS QD even in the presence of air and moisture. Cysteine-capped CdS QD synthesized in the presence of taurine is superior over other cysteinecapped CdS QDs synthesized in the absence of taurine (data not shown).

QDs are photostable and bright and significantly used in biological imaging and diagnostic methods [45-47]. Antibody-conjugated cysteine-capped CdS QD was further applied in QD-linked immunosorbent assays and immunohistochemistry in order to check its binding efficacy and fluorescent ability.

In QD-LISA, microtiter wells processed for immune assays gave sharp fluorescence after exposure to UV light. Observation under a fluorescent microscope confirmed the binding of antibodies with their respective targets. In immunohistochemistry, binding of QD-conjugated antitransferrin antibodies with transferrin bound to transferrin receptor was checked on MDA-MB 231 cancer cells because receptor expression is increased to a thousandfold on cancer 


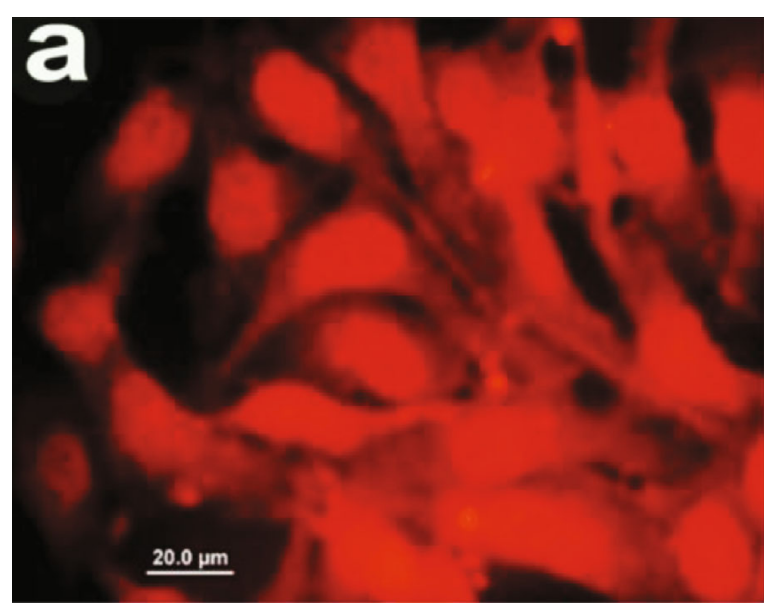

(a)

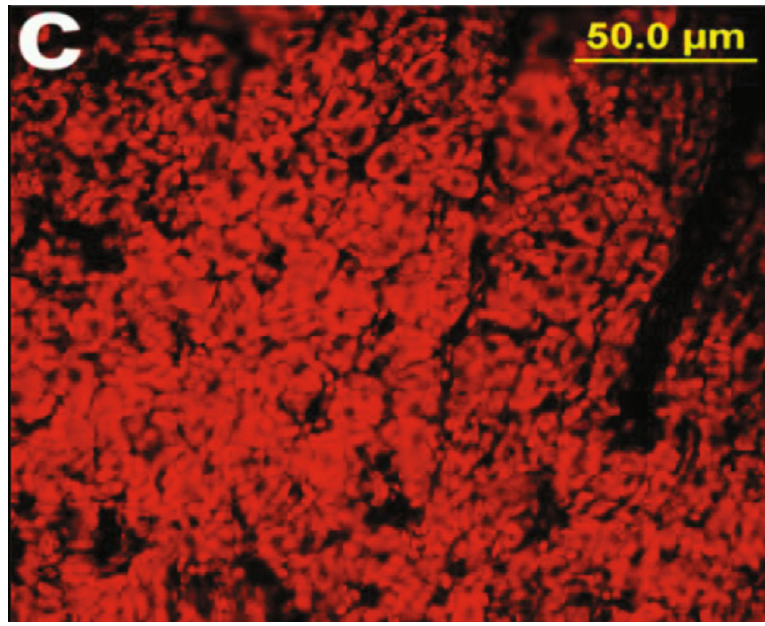

(c)



(b)

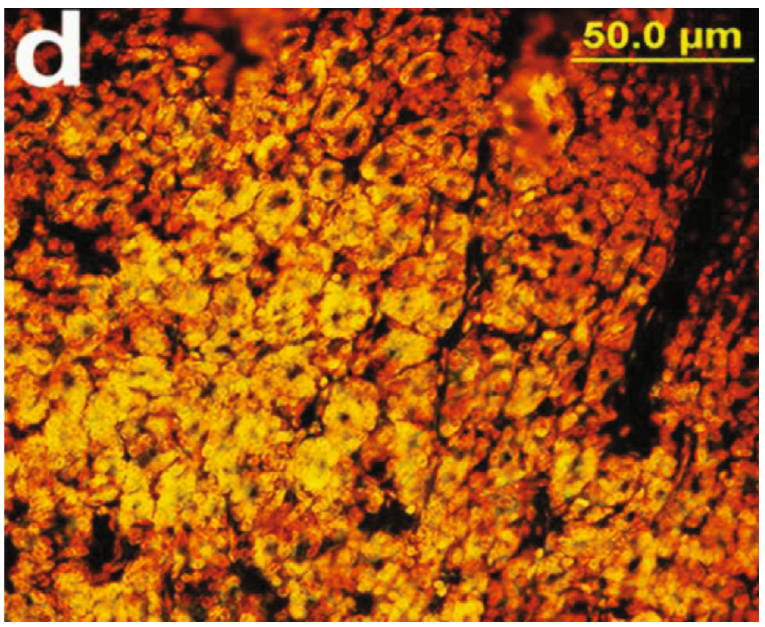

(d)

FIGURE 10: Immunohistochemical study of anti-doxorubicin binding. (a) and (c) confirm the intake of doxorubicin antibody by MDA-MB 231 cancer cells and tumor cells before staining with anti-doxorubicin antibody while (b) and (d) show the stained MDA-MB 231 cancer cells and tumor sections with anti-doxorubicin antibodies.

cells as compared to normal cells $[26,47,48]$ as well as on liver tissue as it is actively involved in the upregulation of iron load for rapid metabolism $[49,50]$. Results showed the successful binding of anti-transferrin antibodies with transferrin receptors. Anti-doxorubicin antibody binding study was done on MDA-MB 231 cells and on mouse mammary gland tumor tissues. Fluorescent studies further confirmed the binding of anti-doxorubicin to doxorubicin that resides on the cells. The binding of anti-H. pylori antibodies with $H$. pylori surface proteins showed fluorescence that confirmed the bindings. This QD-conjugated anti H. pylori may be a good diagnostic tool for $H$. pylori in gastric biopsy samples and laboratory diagnostic tests.

This one-step identification of transferrin receptor or drug in the tissue will be a fruitful pathway in the diagnosis and therapeutic studies. The final size of the nanocomposites was below $45 \mathrm{~nm}$ which can be used for intravenous injection. It is a general observation that the size of nanocomposites in a range of $60 \mathrm{~nm}$ to $100 \mathrm{~nm}$ is considered to be good for targeting drug delivery. Experiments are underway to detect the transferrin receptor expression and the role of $H$. pylori in gastric inflammation in a mouse model.

\section{Conclusion}

This research article summarizes the production of rabbit polyclonal antibodies against different immunogens and discusses their applications after conjugation with cysteinecapped CdS QD as diagnostic and characteristic tools in laboratories and researches, respectively. A new approach for the synthesis of cysteine-capped CdS QD is reported in the presence of taurine (antioxidant). CdS has intrinsic redox properties, and prone toward air oxidation during their growth, an antioxidant not only keeps the particle size to a lower range but also gives high luminescence, best-quality QD nanoparticles. Conjugation of these highly fluorescent particles with produced polyclonal antibodies gives the best diagnostic and characteristic approach in our research laboratory. 


\section{Data Availability}

The Experimental data used to support the findings of this study are included within the article" However, we are here to provide any additional related data on request.

\section{Ethical Approval}

This manuscript complies with the ethical rules applicable for this journal.

\section{Conflicts of Interest}

The authors declare that they have no conflict of interest.

\section{Acknowledgments}

This work was supported by the Institute of Biochemistry and Biotechnology, University of the Punjab, Lahore, Pakistan. Mice with tumors were obtained from AMBR Lab, IBB, University of the Punjab, Lahore, Pakistan.

\section{References}

[1] N. S. Lipman, L. R. Jackson, L. J. Trudel, and F. Weis-Garcia, "Monoclonal versus polyclonal antibodies: distinguishing characteristics, applications, and information resources," ILAR Journal, vol. 46, no. 3, pp. 258-268, 2005.

[2] H. Nasiri, Z. Valedkarimi, L. Aghebati-Maleki et al., "Production and purification of polyclonal antibody against $\mathrm{F}(\mathrm{Ab}$ ')2 fragment of human immunoglobulin G," Veterinary Research Forum : An International Quarterly Journal, vol. 8, 2017.

[3] W. C. Hanly, J. E. Artwohl, and B. T. Bennett, "Review of polyclonal antibody production procedures in mammals and poultry," ILAR Journal, vol. 37, no. 3, pp. 93-118, 1995.

[4] R. Schad, C. Staak, H. Spielman et al., "The production of Avian (Egg Yolk) Antibodies: IgY. The report and recommendations of ECVAM workshop 21," In ATLA Alternatives to Laboratory Animals, vol. 24, 1996.

[5] H. F. Stills, "Polyclonal antibody production," in In The Laboratory Rabbit, Guinea Pig, Hamster, and Other Rodents, Elsevier, 2012.

[6] K. Seekell, H. Price, S. Marinakos, and A. Wax, "Optimization of immunolabeled Plasmonic nanoparticles for cell surface receptor analysis," Methods, vol. 56, no. 2, pp. 310-316, 2012.

[7] M. Bruchez Jr., "Semiconductor nanocrystals as fluorescent biological labels," Science, vol. 281, no. 5385, pp. 2013-2016, 1998.

[8] L. von Bonsdorff, H. Tölö, E. Lindeberg, T. Nyman, A. Harju, and J. Parkkinen, "Development of a pharmaceutical apotransferrin product for iron binding therapy," Biologicals, vol. 29, no. 1, pp. 27-37, 2001.

[9] A. Dautry-Varsat, A. Ciechanover, and H. F. Lodish, "PH and the recycling of transferrin during receptor-mediated endocytosis," Proceedings of the National Academy of Sciences of the United States of America, vol. 80, no. 8, pp. 2258-2262, 1983.

[10] E. P. Skaar, "The battle for iron between bacterial pathogens and their vertebrate hosts," PLoS Pathogens, vol. 6, no. 8, 2010.

[11] F. D. Menozzi, C. Gantiez, and C. Locht, "Identification and purification of transferrin- and lactoferrin-binding proteins of Bordetella pertussis and Bordetella bronchiseptica," Infection and Immunity, vol. 59, no. 11, pp. 3982-3988, 1991.

[12] C. S. Lee, H. Kim, J. Yu et al., "Doxorubicin-loaded oligonucleotide conjugated gold nanoparticles: a promising in vivo drug delivery system for colorectal cancer therapy," European Journal of Medicinal Chemistry, vol. 142, pp. 416-423, 2017.

[13] K. Sintara, D. Thong-Ngam, S. Patumraj, and N. Klaikeaw, "Curcumin attenuates gastric cancer induced by N-methyl$\mathrm{N}$-nitrosourea and saturated sodium chloride in rats," Journal of Biomedicine and Biotechnology, vol. 2012, 8 pages, 2012.

[14] R. W. Ruddon, "Chapter 1: Introduction to the Molecular Biology of Cancer: Translation to the Clinic," in Progress in Molecular Biology and Translational Science, pp. 1-8, Elsevier, 2010.

[15] M. S. Lodhi and Z. Q. Samra, "Purification of transferrin by magnetic nanoparticles and conjugation with cysteine capped gold nanoparticles for targeting diagnostic probes," Preparative Biochemistry and Biotechnology, vol. 49, no. 10, pp. 961973, 2019.

[16] E. Harlow and D. Lane, Using Antibodies: a Laboratory Manual, CSHL Press; 1998, Antibodies A Laboratory Manual Illustrated, 1999.

[17] Z. Q. Samra, S. Ahmad, M. Javeid et al., "Anticancer medicines (doxorubicin and methotrexate) conjugated with magnetic nanoparticles for targeting drug delivery through iron," Preparative Biochemistry and Biotechnology, vol. 43, no. 8, pp. 781-797, 2013.

[18] A. L. Yershov, B. S. Jordan, J. M. Fudge, and M. A. Dubick, "Influence of the mode of ventilation on ketamine/xylazine requirements in rabbits," Veterinary Anaesthesia and Analgesia, vol. 34, no. 3, pp. 157-163, 2007.

[19] E. Harlow and D. Lane, Hybridomas, A Laboratory Manual, 1988.

[20] H. Towbin, T. Staehelin, and J. Gordon, "Electrophoretic transfer of proteins from polyacrylamide gels to nitrocellulose sheets: procedure and some applications," Proceedings of the National Academy of Sciences, vol. 76, no. 9, pp. 4350-4354, 1979.

[21] H. Arefanian and M. Djalali, "A new protocol for isolation and purification of transferrin from human serum," Iranian Journal of Public Health, vol. 31, 2002.

[22] I. S. Trowbridge and M. B. Omary, "Human cell surface glycoprotein related to cell proliferation is the receptor for transferrin," Proceedings of the National Academy of Sciences of the United States of America, vol. 78, no. 5, pp. 3039-3043, 2006.

[23] J. C. Kwok and D. R. Richardson, "The iron metabolism of neoplastic cells: alterations that facilitate proliferation?," Critical Reviews in Oncology/Hematology, vol. 42, no. 1, pp. 65-78, 2002.

[24] R. Luria-Pérez, G. Helguera, and J. A. Rodríguez, "Antibodymediated targeting of the transferrin receptor in cancer cells," Boletín Médico Del Hospital Infantil de México, vol. 73, no. 6, pp. 372-379, 2016.

[25] T. R. Daniels, T. Delgado, G. Helguera, and M. L. Penichet, "The transferrin receptor part II: targeted delivery of therapeutic agents into cancer cells," Clinical Immunology, vol. 121, no. 2, pp. 159-176, 2006.

[26] S. Tortorella and T. C. Karagiannis, "Transferrin receptormediated endocytosis: a useful target for cancer therapy," Journal of Membrane Biology, vol. 247, no. 4, pp. 291-307, 2014. 
[27] T. R. Daniels, P. P. Ng, T. Delgado et al., "Conjugation of an anti transferrin receptor IgG3-avidin fusion protein with biotinylated saporin results in significant enhancement of its cytotoxicity against malignant hematopoietic cells," Molecular Cancer Therapeutics, vol. 6, no. 11, pp. 2995-3008, 2007.

[28] E. Ascione, L. Muscariello, V. Maiello et al., "A simple method for large-scale purification of plasma-derived apo-transferrin," Biotechnology and Applied Biochemistry, vol. 57, no. 3, pp. 8795, 2010.

[29] L. von Bonsdorff et al., "Apotransferrin administration prevents growth ofStaphylococcus epidermidisin serum of stem cell transplant patients by binding of free iron," FEMS Immunology and Medical Microbiology, vol. 37, no. 1, pp. 45-51, 2003.

[30] A. Van Campenhout, C. M. van Campenhout, A. R. Lagrou, and B. Manuel-y-Keenoy, "Transferrin modifications and lipid peroxidation: implications in diabetes mellitus," Free Radical Research, vol. 37, no. 10, pp. 1069-1077.

[31] A. CampenhoutVan, C. Van Campenhout, A. R. Lagrou et al., "Impact of diabetes mellitus on the relationships between iron-, inflammatory- and oxidative stress status," Diabetes/Metabolism Research and Reviews, vol. 22, no. 6, pp. 444-454, 2006.

[32] T.-M. Sun, Y.-C. Wang, F. Wang et al., "Cancer stem cell therapy using doxorubicin conjugated to gold nanoparticles via hydrazone bonds," Biomaterials, vol. 35, no. 2, pp. 836-845, 2014.

[33] H. Guan, M. J. McGuire, S. Li, and K. C. Brown, "Peptide-targeted polyglutamic acid doxorubicin conjugates for the treatment of $\alpha_{\mathrm{v}} \beta_{6}$-positive cancers," Bioconjugate Chemistry, vol. 19, no. 9, pp. 1813-1821, 2008.

[34] L. Gao, J. Yu, L. Yang et al., "Tumor-penetrating peptide conjugated and doxorubicin loaded T 1 -T 2 dual mode MRI contrast agents nanoparticles for tumor theranostics," Theranostics., 2018.

[35] L. Han, R. Huang, S. Liu, S. Huang, and C. Jiang, "Peptide-conjugated PAMAM for targeted doxorubicin delivery to transferrin receptor overexpressed tumors," Molecular Pharmaceutics, 2010.

[36] L. H. Eusebi, R. M. Zagari, and F. Bazzoli, "Epidemiology of Helicobacter pylori infection," Helicobacter, 2014.

[37] S. Backert, M. Neddermann, G. Maubach, and M. Naumann, "Pathogenesis of Helicobacter pylori infection," Helicobacter, 2016.

[38] R. M. Peek and M. J. Blaser, "Helicobacter pylori and gastrointestinal tract adenocarcinomas," Nature Reviews Cancer., 2002.

[39] R. Mera, E. T. H. Fontham, L. E. Bravo et al., "Long term follow up of patients treated for Helicobacter pylori infection," Gut, 2005.

[40] T. H. Burkholder, G. Linton, R. F. Hoyt, and R. Young, "The rabbit as an experimental model," The Laboratory Rabbit, Guinea Pig, Hamster, and Other Rodents, 2012.

[41] M. Suckow, K. Stevens, and R. Wilson, "The Laboratory Rabbit, Guinea Pig, Hamster, and Other Rodents," The Laboratory Rabbit, Guinea Pig, Hamster, and Other Rodents., 2012.

[42] B. Agrawal and P. Maity, "Recent developments for the synthesis of air stable quantum dots," Reviews on Advanced Materials Science, vol. 49, 2017.

[43] C. Bullen and P. Mulvaney, "The effects of chemisorption on the luminescence of CdSe quantum dots," Langmuir, 2006.
[44] R. Dunleavy, L. Lu, C. J. Kiely, S. McIntosh, and B. W. Berger, "Single-enzyme biomineralization of cadmium sulfide nanocrystals with controlled optical properties," Proceedings of the National Academy of Sciences., 2016.

[45] J. E. Francis, D. Mason, and R. Lévy, "Evaluation of quantum dot conjugated antibodies for immunofluorescent labelling of cellular targets," Beilstein Journal of Nanotechnology, 2017.

[46] E. R. Goldman, G. P. Anderson, P. T. Tran, H. Mattoussi, P. T. Charles, and J. Matthew Mauro, "Conjugation of luminescent quantum dots with antibodies using an engineered adaptor protein to provide new reagents for fluoroimmunoassays," Analytical Chemistry., 2002.

[47] P. Ponka and C. N. Lok, "The transferrin receptor: role in health and disease," International Journal of Biochemistry and Cell Biology., 1999.

[48] Z. M. Qian, "Targeted drug delivery via the transferrin receptor-mediated endocytosis pathway," Pharmacological Reviews, 2002.

[49] R. E. Fleming, M. C. Migas, C. C. Holden et al., "Transferrin receptor 2: continued expression in mouse liver in the face of iron overload and in hereditary hemochromatosis," Proceedings of the National Academy of Sciences., 2002.

[50] J.-p. Lu, K. Hayashi, and M. Awai, "Transferrin receptor expression in normal, iron-deficient and iron-overloaded rats," Pathology International., 1989. 